\title{
INDICADORES DE SUSTENTABILIDADE PARA CONSERVAÇÃO GENÉTICA DE Erythrina velutina Willd., EM ÁREA DE MATA CILIAR ${ }^{1}$
}

\author{
Danilla Cristina Lemos Souza², Renata Silva-Mann³ e Marília Freitas de Vasconcelos Melo ${ }^{4}$
}

\begin{abstract}
RESUMO - Um dos grandes desafios para o sistema agropecuário é estabelecer a produção agrícola aliada à conservação dos recursos genéticos, principalmente visando à proteção de Áreas de Preservação Permanente. Nesse contexto, mulungu (Erythrina velutina Willd), entre outras espécies nativas, vem sofrendo com as pressões antrópicas nos mais diversos ecossistemas, o que causa reduções em sua base genética. Este trabalho foi realizado com o objetivo de utilizar parâmetros ecológicos e genéticos populacionais como indicadores de sustentabilidade em duas populações naturais de mulungu, situadas em áreas de floresta ciliar, no Estado de Sergipe, bem como avaliar a tendência à sustentabilidade delas, visando à conservação genética da espécie. Utilizou-se a matriz de Pressão-Estado-Impacto/Efeito-Resposta (PEI/ER) com a seleção de 13 indicadores, a partir do uso de marcadores moleculares RAPD e bioquímicos (enzimas) nas populações, de modo a apresentá-los como informações relevantes para medir o progresso quanto à sustentabilidade e conservação de mulungu. As populações estudadas apresentaram baixa tendência à sustentabilidade, necessitando de estratégias para mudança desse status .
\end{abstract}

Palavras-chave: Mulungu; Espécie nativa; Genética de populações.

\section{INDICATORS OF SUSTAINABILITY FOR GENETIC CONSERVATION OF Erythrinavelutina Willd., IN RIPARIAN FOREST AREA}

\begin{abstract}
One of the greatest challenges for the agricultural system is to establish agricultural production combined with the conservation of genetic resources, mainly aiming to protect the Permanent Preservation Areas. In this context, mulungu (Erythrina velutina Willd), among other native species, has been suffering with anthropogenic pressures in various ecosystems, causing reductions in its genetic basis. This work aims to identify ecological and genetic population parameters as indicators of sustainability in two natural populations of mulungu, located in riparian forest, in the state of Sergipe, and to assess the tendency to their sustainability, aiming genetic conservation of the species.The matrix of Pressure-State-Impact/Effect-Response (PEI/ER)was used with the selection of 13 indicators, from the use of RAPDmolecular markers and biochemical (enzymes) markers in populations, in order to present them as relevant information to measure progress as for sustainability and conservation ofmulungu. The studied populations presented low tendency to sustainability, requiring strategies to change this status.
\end{abstract}

Keywords: Mulungu; Native species; Population genetics

\footnotetext{
${ }^{1}$ Recebido em 09.01.2014 aceito para publicação em 22.09.2014.

${ }^{2}$ Programa de Pós-Graduação em Agroecossistemas, Universidade Federal de Sergipe, UFS, São Cristóvão, Brasil. E-mail: <danillacristina@ig.com.b>.

${ }^{3}$ Departamento de Engenharia Agronômica, Universidade Federal de Sergipe, Centro de Ciências Agrárias Aplicadas, UFS, São Cristóvão, Brasil.E-mail: <renatamann@gmail.com>.

${ }^{4}$ Programa de Pós-Graduação em Ciência Florestal, Universidade Estadual Paulista "Júlio de Mesquita Filho", UNESP, Botucatu, Brasil. E-mail: <mariliafvm@yahoo.com.br>.
} 


\section{INTRODUÇÃO}

Os ecossistemas naturais tendem a ser sustentáveis, visto que, do ponto de vista ecológico, mantêm a produtividade de acordo com a capacidade de suporte do meio, a diversidade genética e as características físico-químicas do solo, entre outros fatores. Em longo prazo, qualquer produção econômica baseada no uso dos recursos naturais será insustentável, se estiver degradando o ecossistema (POGGIANI et al., 1998) e limitando sua capacidade de resiliência. Um dos grandes desafios para o sistema agropecuário é estabelecer a produção agrícola aliada à conservação dos recursos genéticos, principalmente em áreas contempladas pelo Código Florestal Brasileiro.

O mulungu (Erythrina velutina Willd), por apresentar propriedades medicinais de importância (CARVALHO et al., 2009; SANTOS et al., 2012; SILVA et al., 2013) e sua madeira ser útil para o fabrico de tamancos, brinquedos e moirões (LORENZI; MATOS, 2008), tem sido largamente utilizado em algumas regiões do país para tais finalidades. Em razão disso, esta espécie vem sendo explorada de forma indiscriminada, e, no Estado de Sergipe, é crescente a retirada de seus indivíduos para abertura de áreas de pastagem e construção de estradas em Áreas de Preservação Permanente (APPs), neste caso as matas ciliares, que são consideradas área protegidas pela Lei n. 12.651/ 2012 (BRASIL, 2012).

A fragmentação dos hábitats pode propiciar, além da perda da diversidade genética, a extinção das populações arbóreas, o que torna eminente a necessidade de se conservá-las. A definição de um programa de conservação dessas populações requer o conhecimento de padrões ecológicos e genéticos das espécies (REIS et al., 2009). Para tanto, para determinação dessa diversidade, podem ser utilizados marcadores genéticos, de modo a quantificar os principais efeitos da fragmentação e exploração de espécies nativas de valor econômico, possibilitando, assim, a elaboração de estratégias eficientes (VIEIRA; CARVALHO, 2008; MOURA et al., 2011).

Associado a isso, as ações propostas na Agenda 21, com ênfase na definição de indicadores ambientais, vêm possibilitar um aperfeiçoamento nos modelos de gerenciamento dos recursos naturais (HOLANDA et al., 2008). Os indicadores de sustentabilidade, principalmente em áreas que sofrem constante ação antrópica, permitem estabelecer relações de causa-efeito e fazer previsões sobre o comportamento, em médio e em longo prazo, quanto à sustentabilidade dos ecossistemas (POGGIANI et al., 1998). Assim, com o crescente interesse na conservação de florestas nativas, torna-se importante a definição de indicadores de sustentabilidade que possam servir de referência para a avaliação dos fragmentos, quanto à sua capacidade de manutenção de espécies consideradas importantes (GANDARA; KAGEYAMA, 1998).

Nesse sentido, este trabalho foi realizado com os objetivos de utilizar estimativas de parâmetros ecológicos e genéticos populacionais como indicadores de sustentabilidade em matas ciliares e avaliar a tendência à sustentabilidade de populações de mulungu em caráter de raridade, com vista à sua conservação genética e ao uso dos indicadores, aqui selecionados para outras espécies nativas em APPs.

\section{MATERIAL E MÉTODOS}

O objeto de estudo foi a obtenção de estimativas ecológicas, de estrutura e diversidade genética, por meio de marcadores RAPD (Random Amplified Polymorphic - DNA) e enzimáticos, de duas populações naturais de mulungu, contidas em área de 100 ha cada, no Estado de Sergipe. A primeira população está localizada no Município de Santana do São Francisco (10¹5’55" S e 36 38'15"W), que apresenta clima do tipo megatérmico seco a subúmido com temperatura média anual de 26 ${ }^{\circ} \mathrm{C}$, precipitação pluviométrica média anual de 1.200 mm e período chuvoso de março a agosto, com vegetação de Mata Atlântica e Capoeira. A segunda encontra-se no Município de Pinhão (10³3’50" S e 37²42’47" W), área de exploração agropecuária que está inserida no polígono das secas, com clima do tipo megatérmico seco, temperatura média anual de $24^{\circ} \mathrm{C}$, precipitação pluviométrica média ao ano de $800 \mathrm{~mm}$ e período chuvoso de março a agosto, com vegetação de Caatinga e Capoeira (SERGIPE; SEPLANTEC/SUPES, 2000).

A população de Santana do São Francisco foi composta por 20 indivíduos de mulungu e a de Pinhão, por 19 indivíduos. O número reduzido de indivíduos estudados deve-se, principalmente, ao processo de ocupação humana que ocorreu nas vegetações ciliares e outras áreas do Estado de Sergipe, promovendo o isolamento dos fragmentos (SOUZA et al., 2013). Visitas às populações foram realizadas durante todo o ano 2013, para coleta de material. 
Para o marcador RAPD, foram realizadas amplificações aleatórias de porções do genoma de indivíduos da espécie. Utilizaram-se 20 oligonucleotídeos da marca IDT (Integrated DNA Technologies) (Tabela 1) em cada um dos indivíduos estudados/população. Para a caracterização da diversidade genética, foi utilizado o programa POPGENE (Population Genetic Analysis) versão 1.32 (YEH et al., 1999), empregando-se parâmetros para dados diploides dominantes. Tendo em vista a natureza dominante dos dados, esse programa pressupõe, para os cálculos das estimativas das frequências alélicas, que os locos estão em Equilíbrio de Hardy-Weinberg (EHW). Foi estimada a porcentagem de locos polimórficos $(P)$, o número de alelos observados, o número de alelos efetivos, a heterozigosidade $\left(\hat{H}_{e}\right)$ e o índice de Shannon (I) para cada população e para o conjunto de populações. Também, foi realizada a análise de diversidade genética entre populações pelo método de Nei e a estimativa do fluxo gênico $\left(N_{m}\right)$.

Nas análises enzimáticas, testaram-se 15 sistemas, dos quais seis foram empregados nas estimativas de parâmetros genéticos, por serem passíveis de

Tabela 1 - Sequências de oligonucleotídeos utilizados nas reações de RAPD em indivíduos de mulungu (Erythrina velutina Willd), em áreas de mata ciliar.

Table 1 -Sequencesofoligonucleotides used in RAPD reactionsin individuals ofmulungu (Erythrina velutina Willd) in riparian forestareas.

\begin{tabular}{cc}
\hline Oligonucleotídeos & Seqüências $\left(5^{\prime}-3^{\prime}\right)$ \\
\hline IDT 01 & CAG GCC CTT C \\
IDT 02 & TGC CGA GCT G \\
IDT 03 & GTT TCG CTC C \\
IDT 04 & TGA TCC CTG G \\
IDT 05 & TTC GAG CCA G \\
IDT 06 & GTG AGG CGT C \\
IDT 07 & ACC GCG AAG G \\
IDT 08 & GGA CCC AAC C \\
IDT 09 & CCC AAG GTC C \\
IDT 10 & GGT GCG GGA A \\
IDT 11 & ACG GAT CCT G \\
IDT 12 & GAG GAT CCC T \\
IDT 13 & CTA CGG AGG A \\
IDT 14 & GGC ACT GAG G \\
IDT 15 & GGT CGG AGA A \\
IDT 16 & TCG GAC GTG A \\
IDT 17 & ACC TGG ACA C \\
IDT 18 & GGA GGA GAG G \\
IDT 19 & CCC GGC ATA A \\
IDT 20 & AAA GTT GGG A \\
\hline
\end{tabular}

interpretação: Esterase - EST; Isocitrato Desidrogenase - IDH; Malato Desidrogenase - MDH; Superóxido Dismutase - SOD; Glucose-6-Fosfato Desidrogenase - G6PDH; e Peroxidase - PO. Por meio da interpretação dos zimogramas, obtiveram-se as frequências alélicas de cada loco, a partir das quais foram obtidos os índices de diversidade genética: porcentagem de locos polimórficos ( $P$ ); número médio de alelos por loco $(A)$; heterozigosidade média observada $\left(H_{o}\right)$; e heterozigosidade média esperada $\left(\hat{H}_{\mathrm{e}}\right)$, de acordo com o EHW. A estrutura genética foi avaliada pelo coeficiente de endogamia F de Wright, ou índice de fixação, para a média das populações $\left(\hat{F}_{15}\right)$, com base nas estimativas das frequências observadas $\left(\hat{H}_{o}\right)$ e esperadas $\left(\hat{H}_{\mathrm{e}}\right)$ de heterozigotos. Essas estimativas foram obtidas por meio do programa POPGENE 1.32. (YEH et al., 1999).

A seleção dos indicadores de sustentabilidade foi realizada com base na metodologia proposta pela Organização para a Cooperação e Desenvolvimento Econômico e adaptada pelo Programa das Nações Unidas para o Meio Ambiente, em 1996, a denominada matriz de indicadores de Pressão-Estado-Impacto/ Efeito-Resposta (PEI/ER) (WINOGRAD et al., 1996).

Visando obter o levantamento da lista de indicadores, inicialmente, foram definidos descritores, considerando as categorias: Pressão - pressões diretas e indiretas sobre o meio ambiente em consequência das interações sociedade/natureza; Estado - estado em que se encontra o ambiente, em consequência das pressões sofridas pelas atividades antrópicas nos diversos ambientes; Impacto/efeito - relacionado com os efeitos e impactos das interações sociedade/ natureza, referentes às funções ecológicas dos ecossistemas, dos recursos e dos impactos sobre a sociedade (essa categoria muda em função das respostas que a sociedade gera sobre o meio ambiente); e Resposta - ações que a sociedade gera como resposta às pressões, estados e efeitos sobre o meio ambiente, conduzindo os processos de desenvolvimento e uso dos recursos naturais, de modo a aliviar e, ou, prevenir os impactos econômicos, sociais e ambientais negativos (WINOGRAD et al., 1996).

Para obtenção das estimativas generalizadas para as populações, foi realizada uma média aritmética dos valores obtidos de cada população de mulungu.

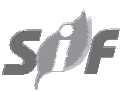

Revista Árvore, Viçosa-MG, v.38, n.6, p.1103-1113, 2014 


\section{RESULTADOS}

Selecionaram-se oito descritores (Pressões antrópicas; Capacidade de regeneração da espécie; Vigor dos genótipos; Estrutura e diversidade genética; Erosão genética; Endogamia; Produção Científica; e Conservação ex situ), que resultaram em 13 indicadores. Os descritores foram escolhidos de acordo com o que foi medido das condições reais ou comparado com as condições de referência (Tabela 2).

Os indicadores estão dispostos conforme definição da matriz PEI/ER, sendo eles: Densidade da espécie $\left(n^{\circ} . h^{-1}\right)$; Densidade de plântulas $\left(n^{\circ} . m^{2-1}\right)$; Altura (m); DAP (Diâmetro à altura do peito - $\mathrm{cm}$ ); Fragmentos polimórficos de DNA amplificados $\left(\mathrm{n}^{\circ}\right)$; Locos polimórficos (\%); Índice de Shannon [0,0 - 1,0]; Diversidade genética entre populações (\%); Heterozigosidade [-1,0 - 1,0]; Fluxo gênico $(<1,0)$; Coeficiente de endogamia [-1,0 - 1,0]; Publicações $\left(n^{\circ}\right)$; e BAGs - Bancos Ativos de Germoplasma (nº) (Tabela 3).

\subsection{Indicadores de Pressão (P)}

\subsubsection{Densidade da espécie $\left(\mathrm{n}^{0} . \mathrm{ha}^{-1}\right)$}

Refere-se ao número de indivíduos de mulungu, em populações naturais, em 1 ha. Uma floresta tropical típica tem como característica principal a de possuir grande número de espécies arbóreas, com variação entre elas em termos de longevidade e papel sucessional. Espécies típicas de grupos funcionais têm características bem determinadas, funcionando como padrões de referência, que podem ser gerais para a maioria das florestas tropicais, independentemente de sua composição florística (GANDARA; KAGEYAMA, 1998). A redução do tamanho populacional de espécies, devido às atividades antrópicas, compromete seriamente a sustentabilidade do ecossistema a ser preservado.

\subsubsection{Densidade de plântulas $\left(\mathbf{n}^{0} . \mathrm{m}^{2-1}\right)$.}

Diz respeito à quantidade de plântulas de mulungu existentes em $1 \mathrm{~m}^{2}$, em torno de um indivíduo adulto, para avaliação da regeneração natural da espécie. Em áreas conservadas, a existência de plântulas de espécies pioneiras dependerá da abertura de clareiras para ativação do banco de sementes existente no solo, além das condições físicas e fisiológicas dessas sementes. Já em áreas perturbadas, é o nível de interferência antrópica que irá determinar a capacidade de regeneração natural dos fragmentos e sua consequente tendência à sustentabilidade, com a manutenção de populações naturais durante as gerações.

\subsection{Indicadores de Estado (E)}

\subsubsection{Altura (m) e Diâmetro àAltura do Peito-DAP(cm)}

Cada espécie, em geral, apresenta uma média de crescimento para indivíduos adultos. Caracteres dendrométricos, como a altura e o DAP, podem ser indicadores de vigor em espécies arbóreas e possibilita

Tabela 2 - Descritores e indicadores de sustentabilidade selecionados para avaliar a conservação genética de mulungu(Erythrina velutinaWilld) em áreas de mata ciliar.

Table 2 - Sustainability descriptors and indicators selected to assess the genetic conservation of mulungu (Erythrina velutina Willd) in riparian forest areas.

\begin{tabular}{|c|c|}
\hline Descritores & Indicadores \\
\hline Pressões antrópicas & Densidade da espécie $\left(\mathrm{n}^{\circ} . \mathrm{ha}^{-1}\right)$ \\
\hline Capacidade de regeneração da espécie & Densidade de plântulas $\left(\mathrm{n}^{\circ} \cdot \mathrm{m}^{2-1}\right)$ \\
\hline \multirow[t]{2}{*}{ Vigor dos genótipos } & Altura (m) \\
\hline & DAP (Diâmetro à altura do peito - cm) \\
\hline \multirow[t]{5}{*}{ Estrutura e diversidade genética } & Fragmentos polimórficos de DNA amplificados $\left(\mathrm{n}^{\circ}\right)$ \\
\hline & Locosgênicos polimórficos (\%) \\
\hline & Heterozigosidade $[-1,0-1,0]$ \\
\hline & Índice de Shannon $[0,0-1,0]$ \\
\hline & Diversidade genética entre populações (\%) \\
\hline Erosão genética & Fluxo gênico $(<1,0)$ \\
\hline Endogamia & Coeficiente de endogamia $[-1,0-1,0]$ \\
\hline Produção científica & Publicações $\left(\mathrm{n}^{\circ}\right)$ \\
\hline Conservação ex situ & Banco Ativo de Germoplasma $\left(n^{\circ}\right)$ \\
\hline
\end{tabular}

Revista Árvore, Viçosa-MG, v.38, n.6, p.1103-1113, 2014 
Tabela 3 - Indicadores de sustentabilidade utilizados para avaliar a conservação genética do mulungu (Erythrina velutinaWilld) em áreas de mata ciliar - matriz de Indicadores Pressão-Estado-Impacto/Efeito-Resposta (PEI/ER).

Table 3 - Sustainability indicators used to assess the genetic conservation of mulungu (ErythrinavelutinaWilld) in riparian forest areas -matrix of Pressure-State-Impact/Effect-Response (PSI/ER).

\begin{tabular}{ll}
\hline Indicadores de Pressão (P) & Densidade da espécie $\left(\mathrm{n}^{\circ} . \mathrm{ha}^{-1}\right)$ \\
& Densidade de plântulas $\left(\mathrm{n}^{\circ} \cdot \mathrm{m}^{2-1}\right)$ \\
\hline Indicadores de Estado (E) & Altura $(\mathrm{m})$ \\
& DAP (Diâmetro à altura do peito - cm) \\
& Fragmentos polimórficos de DNA amplificados $\left(\mathrm{n}^{\circ}\right)$ \\
& Locos polimórficos $(\%)$ \\
& Índice de Shannon $[0,0-1,0]$ \\
& Diversidade genética entre populações (\%) \\
\hline Indicadores de Impacto/Efeito (I/E) & Heterozigosidade $[-1,0-1,0]$ \\
& Fluxo gênico $(<1,0)$ \\
& Coeficiente de endogamia $[-1,0-1,0]$ \\
\hline Indicadores de Resposta (R) & Publicações $\left(\mathrm{n}^{\circ}\right)$ \\
& BAG - Bancos ativos de germoplasma $\left(\mathrm{n}^{\circ}\right)$ \\
\hline
\end{tabular}

a escolha de matrizes porta-sementes, quando associados a uma produção regular de sementes e às condições fitossanitárias do indivíduo.

\subsubsection{Fragmentos polimórficos de DNA amplificados} $\left(\mathbf{n}^{\mathbf{0}}\right)$

Esse indicador refere-se às diferenças genéticas entre os indivíduos de mulungu em cada população. Em espécies alógamas, a perda de diversidade genética promove a redução do potencial que as populações naturais têm de se adaptar às mudanças ambientais e implica na sobrevivência das espécies.

\subsubsection{Locos polimórficos (\%)}

Relaciona-se à ocorrência, em um conjunto de indivíduos de mulungu, de dois ou mais alelos para locos gênicos, com apreciável frequência. Para esses valores, adotou-se o critério de 95\% de probabilidade, em que um loco é considerado polimórfico se a frequência do alelo mais comum não excede $95 \%$ (o critério 95\% é recomendado quando o tamanho amostral é menor que 50 indivíduos). Essa medida foi obtida pela razão entre o número de locos polimórficos pelo número total de locos (MARTINS-CORDER et al., 2009).

\subsection{4. Índice de Shannon $(I)[0,0-1,0]$}

O índice de Shannon foi empregado para medir a diversidade gênica em populações de mulungu e é utilizado em estudos de recursos genéticos como medida de riqueza e uniformidade alélica. Baixos valores indicam ausência de diversidade genética.

\subsubsection{Diversidade genética entre populações (\%)}

Indica quanto da diversidade genética está partilhada entre as populações de mulungu e contribui para a heterozigosidade. Valores reduzidos desse parâmetro implicam estruturação das populações.

\subsection{Indicadores de Impacto/Efeito (I/E)}

\subsubsection{Heterozigosidade $[-1,0-1,0]$}

A heterozigosidade relaciona-se diretamente com o valor adaptativo dos indivíduos de mulungu. Populações naturais que apresentam baixas estimativas para esse parâmetro têm sua sustentabilidade reduzida, pois pode culminar em erosão genética pela perda de alelos. A maioria dos índices de diversidade genética depende da estimativa da heterozigosidade na população (FREIRE et al., 2007).

\subsubsection{Fluxo gênico $(<1,0)$}

Refere-se aos mecanismos que geram movimentos de genes (pólen e semente) de uma população para outra. O impedimento do fluxo gênico acarreta redução nos níveis de diversidade genética das populações arbóreas, o que compromete a sustentabilidade dos ecossistemas.

Revista Árvore, Viçosa-MG, v.38, n.6, p.1103-1113, 2014 


\subsubsection{Coeficiente de endogamia $[0,0-1,0]$}

Trata-se da probabilidade de dois alelos em um único loco, tomados ao acaso de uma população, serem idênticos por descendência. Esse coeficiente mede a redução da heterozigose a partir do EHW e varia de acordo com o sistema de cruzamento da espécie (WRIGHT, 1922).

\subsection{Indicadores de Resposta}

\subsubsection{Publicações $\left(n^{0}\right)$}

Considera-se como publicações a divulgação de artigos científicos sobre a conservação genética da espécie. Valores desse indicador foram baseados em pesquisas com as seguintes palavras-chave dos termos Erythrina velutina e, ou, mulungu: Conservação genética; Conservação; Variabilidade genética; e Diversidade genética, considerando os trabalhos que apresentaram esses termos no título e, ou, resumo. As bases de dados utilizadas nesta pesquisa foram: Science Direct, Scientific Electronic Library Online (SciELO), Web of Science e Scopus.

\subsubsection{Bancos Ativos de Germoplasma-BAGs $\left(\mathrm{n}^{\circ}\right)$}

Considera-se o número de BAGs. Esses bancos possibilitam o intercâmbio de material genético e permitem o armazenamento, por um longo período de tempo, da diversidade genética nas populações naturais. Como a ação antrópica é desenfreada, armazenar genótipos pode favorecer o estabelecimento de plantios em outras áreas, ou seja, ex situ, e dessa forma preservar alelos da espécie. Para obtenção desse indicador, foi utilizada a mesma metodologia para o indicador “publicações”, com palavras-chave para os termos Erythrina velutina e, ou, mulungu: Conservação ex situ; Banco de genes; e Banco Ativo de Germoplasma.

Os indicadores mensurados, com limites para avaliação da tendência de sustentabilidade nas populações naturais de mulungu, são apresentados na Tabela 4.

Para a maioria dos indicadores selecionados, as populações apresentaram baixa tendência à sustentabilidade, com alta tendência para os indicadores DAP, fragmentos polimórficos, locos gênicos polimórficos, heterozigosidade e coeficiente de endogamia.

As estimativas indicadas neste trabalho poderão ser extrapoladas para uso com outras espécies nativas em APPs, uma vez que publicações têm sido geradas em pesquisa sobre a temática. As informações disponíveis na literatura podem contribuir para controle

Tabela 4-Matriz de tendência de sustentabilidade utilizada para avaliar a conservação genética do mulungu (Erythrina velutinaWilld) em duas populações naturais, situadas em áreas de mata ciliar, no Estado de Sergipe.

Table 4 - Sustainability trend matrix used to assess the genetic conservation of mulungu (Erythrina velutinaWilld) in two natural populations, located in riparian forest areas, in the State of Sergipe.

\begin{tabular}{|c|c|c|c|c|c|c|c|}
\hline & \multirow[t]{2}{*}{ Indicadores } & \multicolumn{2}{|c|}{ Populações } & \multirow[t]{2}{*}{$\begin{array}{l}\text { Média das } \\
\text { populações }\end{array}$} & \multicolumn{3}{|c|}{$\begin{array}{l}\text { Tendência de } \\
\text { Sustentabilidade }\end{array}$} \\
\hline & & 1 & 2 & & Baixa & Média & Alta \\
\hline \multirow[t]{2}{*}{ Pressão } & Densidade da espécie $\left(\mathrm{n}^{\circ}\right.$. ha $\left.^{-1}\right)$ & 20 & 19 & 19,50 & $\mathrm{X}$ & & \\
\hline & Densidade de plântulas $\left(\mathrm{n}^{\circ} \cdot \mathrm{m}^{2-1}\right)$ & 0 & 0 & 0 & $\mathrm{X}$ & & \\
\hline \multirow[t]{4}{*}{ Estado } & Altura (m) & 7,95 & 9,10 & 8,52 & & $\mathrm{X}$ & \\
\hline & $\mathrm{DAP}(\mathrm{cm})$ & 84 & 86 & 85 & & & $\mathrm{X}$ \\
\hline & Fragmentos Polimórficos $\left(\mathrm{n}^{\circ}\right)$ & 100 & 112 & 106 & & & $\mathrm{X}$ \\
\hline & Locos gênicos polimórficos (\%) & 81,30 & 90,24 & - & & & $\mathrm{x}$ \\
\hline \multirow[t]{5}{*}{ Impacto/Efeito } & Heterozigosidade $[-1,0-1,0]$ & 0,41 & 0,56 & 0,51 & & & $\mathrm{X}$ \\
\hline & Índice de Shannon $[0,0-1,0]$ & 0,42 & 0,45 & 0,55 & & $\mathrm{X}$ & \\
\hline & Diversidade entre populações (\%) & $*$ & $*$ & 21 & $\mathrm{X}$ & & \\
\hline & Fluxo gênico $(<1)$ & * & $*$ & $-1,91$ & $\mathrm{X}$ & & \\
\hline & $\begin{array}{l}\text { Coeficiente de endogamia } \\
{[-1,0-1,0]}\end{array}$ & * & * & $-0,51$ & & & $\mathrm{X}$ \\
\hline \multirow[t]{2}{*}{ Resposta } & Publicações $\left(\mathrm{n}^{\circ}\right)$ & $*$ & $*$ & 2 & $\mathrm{X}$ & & \\
\hline & $\operatorname{BAG}\left(\mathrm{n}^{\circ}\right)$ & * & * & 0 & $X$ & & \\
\hline
\end{tabular}

População 1 - Santana do São Francisco; População 2 - Pinhão; DAP - Diâmetro à altura do peito; BAG - Banco Ativo de Germoplasma; (-) - Parâmetro não calculado; (*) - Não existe valor para o parâmetro.

Revista Árvore, Viçosa-MG, v.38, n.6, p.1103-1113, 2014 
e monitoramento da conservação ajustados aos diferentes ecossistemas.

\section{DISCUSSÃO}

Levando em conta que a fragmentação de florestas pode resultar em mudanças na composição florística ao longo do tempo, esperava-se que o mulungu, espécie pioneira (LORENZI; MATOS, 2008), fosse encontrado, juntamente com outras espécies do mesmo grupo ecológico, em maior abundância que espécies dos demais grupos, como ressaltado por Nascimento et al. (1999). Ao estudar a estrutura e dinâmica de populações arbóreas em um fragmento de vegetação Estacional Semidecidual, esses mesmos autores observaram as pioneiras como espécies mais abundantes, com grande representatividade de indivíduos para cada espécie. Isso não foi observado nas áreas estudadas, o que indica baixa densidade de indivíduos, decorrente do intenso uso da espécie no Estado de Sergipe, sendo, portanto, fator preocupante para a manutenção das populações naturais de mulungu em longo prazo. Baixa ocorrência de indivíduos de mulungu (apenas três indivíduos) também foi constatada por Silva et al. (2014), que avaliaram a composição da comunidade de plantas em cinco regiões semiáridas do Estado da Paraíba, Nordeste do Brasil, em três diferentes gradientes de altitude, concluindo-se que a atividade antrópica têm alterado o padrão de riqueza vegetal na Caatinga. Em relação à densidade de plântulas, nenhuma plântula foi encontrada próxima aos indivíduos, podendo esse fato ser atribuído à intensa presença de ação antrópica nas áreas estudadas (abertura de estradas, pastoreio, agricultura etc.).

O mulungu é uma espécie arbórea que pode atingir dimensões de até $15 \mathrm{~m}$ de altura e $80 \mathrm{~cm}$ de DAP na idade adulta (CARVALHO, 2008). Valores próximos são encontrados para ambas as populações, o que indica que os indivíduos remanescentes ainda se apresentam vigorosos para as características dendrométricas.

O número de fragmentos polimórficos utilizados na avaliação da diversidade genética em plantas é bastante variável. Com marcadores RAPD, Gomes Filho et al. (2010) utilizaram 117 fragmentos de DNA polimórficos para a caracterização da diversidade genética em acessos de goiabeiras (Psidium guajava L.), e Rabanni et al. (2012) empregaram 74 no estudo de diversidade genética de uma população de jenipapo (Genipa americana L.). Já Valle et al. (2013), ao analisarem a estrutura genética de cinco populações de pariparoba (Pothomorphe umbellata (L.)), basearam-se em 25 fragmentos polimórficos. A média obtida neste estudo de 106 fragmentos polimórficos, utilizando o mesmo marcador molecular, foi eficiente no estudo genético das populações de mulungu, inferindo em a existência de diversidade genética dessas.

Observaram-se valores de locos gênicos polimórficos de $81,30 \%$ e $90,24 \%$, respectivamente das populações de Santana do São Francisco e Pinhão. Esses resultados são considerados relativamente altos para populações naturais de espécies arbóreas, mostrando-se favoráveis à conservação in situ (GOIS et al., 2009), com vista à manutenção da diversidade genética ao longo das gerações.

A heterozigosidade observada no conjunto de populações foi de 0,51 , sendo considerada de alta magnitude $(>0,15)$ (OLIVEIRA et al., 2006). Altos níveis de heterozigosidade são comuns em populações com grande número de indivíduos, pois os efeitos da endogamia e erosão genética são reduzidos, o que culmina em ampla diversidade genética. Porém, elevada heterozigosidade pode ser encontrada também em populações fragmentadas (NAZARENO; JUMP, 2012), decorrentes de um processo recente de gargalo genético e, ou, da estratégia de polinização, que, no caso do mulungu, é a cruzada (alogamia/xenogamia). A análise desse parâmetro revela significativa tendência à sustentabilidade das populações de mulungu estudadas, devido à manutenção da diversidade genética, sendo um bom indicador, já que essa espécie está sujeita à grande pressão antrópica (VALLE et al., 20013).

Por meio da análise do índice de Shannon, pode-se inferir acerca de uma média diversidade genética dentro de cada população analisada (BOTREL et al., 2006). O valor médio das populações obtido com esse índice $(0,55)$ apresenta acréscimo viável, confirmando a necessidade de conservação de ambas as populações de mulungu, pois estas apresentam alelos efetivos diferenciados, o que aumenta a base genética da espécie.

A partir da estimativa da diversidade genética entre as populações de mulungu, pode-se inferir que a diversidade amostrada entre as populações contribui com $21 \%$ para a heterozigosidade, sendo $79 \%$ da diversidade distribuída dentro das populações. A alta diferenciação genética observada é indicativo de que essas populações de mulungu estão estruturadas geneticamente, o que pode ser consequência da 
fragmentação do hábitat, do tamanho reduzido de ambas as populações, e, ainda, da existência de baixo nível de fluxo gênico entre elas (NAIR et al., 2014). Ao estudar populações naturais de Myracrodruon urundeuva Fr. All., localizadas em Aramina, SP, e Selvíria, MS, Viegas et al. (2011) detectaram alta diferenciação genética entre as duas populações, tanto a partir do pólen quanto dos óvulos (15,9\% e 23,5\%, respectivamente), e atribuiu esses resultados à grande distância que separa as populações, somada à deriva genética que cada uma experimenta.

Espécies arbóreas de diferentes grupos sucessionais apresentam padrões característicos de estrutura genética, sendo nas espécies pioneiras esperado fluxo gênico de curta distância (KAGEYAMA et al., 2003). No entanto, isso não foi observado nas populações de mulungu, que não apresentaram ocorrência de fluxo gênico (1,91). A ausência da movimentação de genes entre populações vegetais pode ser considerada como indicativo de isolamento geográfico e reprodutivo delas, em decorrência da distância geográfica entre elas, que as torna vulneráveis a eventos ambientais, demográficos e genéticos, causando reduções (VIEGAS et al., 2011).

As populações de mulungu estudadas apresentaram tendência ao excesso de heterozigotos, em relação ao EHW. Essa informação pode ser confirmada pelo valor do coeficiente de endogamia $(-0,51)$, uma vez que valores negativos indicam ausência de endogamia (OLIVEIRA et al., 2006). Apesar de essa estimativa oferecer alta tendência à sustentabilidade, a adoção de práticas conservativas para essas populações é imprescindível, diante das condições de degradação florestal das áreas em questão.

A preocupação com a conservação de recursos genéticos de plantas vem tomando cada vez mais impulso, mobilizando os meios científicos e os órgãos de controle ambiental. Após a reunião organizada pela FAO/IBP, em 1967, inúmeras publicações importantes têm abordado o tema, direcionando-o aos pontos críticos e propondo formas de minimizar os problemas de perdas irreversíveis dos recursos genéticos (KAGEYAMA, 1987). No entanto, até o momento, constam na literatura apenas duas publicações referentes à conservação do mulungu (GONÇALVES et al., 2014; SILVA et al., 2014) e nenhum banco ativo de germoplasma da espécie.

A amostra reduzida utilizada neste estudo indica a baixa tendência à sustentabilidade das populações de mulungu e permite identificar a necessidade imediata de se estabelecerem estratégias de conservação para espécie, visando promover a manutenção dessas populações ao longo do tempo. A fragmentação da vegetação natural, ocasionada principalmente pela ocupação humana no Estado de Sergipe, tem levado à existência de pequenas populações isoladas, que podem culminar, em último caso, na extinção da espécie no entorno dessa área. Diante do cenário de devastação das áreas de floresta, nesta região estudos que contemplam genótipos prioritários de diferentes espécies arbóreas para conservação são insuficientes (GONÇALVES et al., 2014). Há pouco tempo, alguns trabalhos sobre o tema vêm sendo desenvolvidos (SANTANA et al., 2008; GOIS et al., 2009; SANTOS et al., 2010; COSTA et al., 2011; SILVA et al., 2011; RABBANI et al., 2012; SOUZA et al., 2013; GOIS et al., 2014; GONÇALVES et al., 2014).

\section{CONCLUSÃO}

As estimativas ecológicas e genéticas populacionais podem ser utilizadas como indicadores de sustentabilidade em matas ciliares, principalmente para fins de definição de políticas públicas, visando ao monitoramento de APPs e à conservação da diversidade genética.

Por meio do índice de Shannon, confirma-se a necessidade de conservação de ambas as populações de mulungu, as quais apresentam alelos efetivos diferenciados em cada população.

A variabilidade amostrada entre as populações contribui para a heterozigosidade. Portanto, a divergência genética entre as populações de mulungu é considerada elevada e está estruturada geneticamente.

A amostra reduzida utilizada neste estudo indica a baixa tendência à sustentabilidade das populações e permite identificar a necessidade imediata de se estabelecerem estratégias de conservação para espécie, visando promover a manutenção dessas populações no longo prazo e a recuperação de corredores ecológicos entre elas.

Assim, sugere-se a introdução de indivíduos geneticamente divergentes, bem como equilíbrio no número de indivíduos masculinos e femininos, possibilitando a livre circulação de genes entre fragmentos.

Revista Árvore, Viçosa-MG, v.38, n.6, p.1103-1113, 2014

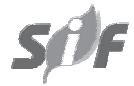




\section{REFERÊNCIAS}

BRASIL. LEI 12.651 de 25 de maio de 2012. Dispõe sobre a proteção da vegetação nativa; altera as Leis nos 6.938, de 31 de agosto de 1981, 9.393, de 19 de dezembro de 1996, e 11.428 , de 22 de dezembro de 2006; revoga as Leis nos 4.771, de 15 de setembro de 1965, e 7.754, de 14 de abril de 1989, e a Medida Provisória no 2.166-67, de 24 de agosto de 2001; e dá outras providências.

Diário Oficial da União, Brasília, DF, 25 maio 2012. p.1.

BOTREL, M.C.G.; SOUZA, A.M.; CARVALHO D.; PINTO, S.I.C.; MOURA, M.C.O.; ESTOPA, R.A. Caracterização genética de Calophyllum brasiliense camb. em duas populações de mata ciliar. Revista Árvore, v.30, n.5, p.821-827, 2006.

CARVALHO, A.C.; ALMEIDA, D.S.; MELO, M.G.; CAVALCANTI, S.C.; MARÇAL, R.M. Evidence of the mechanism of action of Erythrina velutina Willd (Fabaceae) leaves aqueous extract. Journal of

Ethnopharmacology, v.122, n.2, p.374-378, 2009.

CARVALHO, P. E. R. Espécies arbóreas brasileiras. Brasília, DF: Embrapa Informação Tecnológica; Colombo: Embrapa Florestas, 2008. v.3.

COSTA, T.S.; SILVA, A.V.C.; LÉDO, A.S.;

SANTOS, A.R.F.; SILVA JÚNIOR, J.F. Diversidade genética de acessos do banco de germoplasma de mangaba em Sergipe. Pesquisa

Agropecuária Brasileira, v.46, n.5, p.499508, 2011.

FREIRE, J.M.; PIÑA-RODRIGUES, F.C.M.; LIMA, E.R.; SODRÉ, S.R.C.; CORRÊA, R.X. Estrutura genética de populações de Schizolobium parahyba (Vell.) Blake (guapuruvu) por meio de marcadores RAPD. Scientia Forestalis, n.74, p.27-35, 2007.

GANDARA, F. B.; KAGEYAMA, P. Y. Indicadores de sustentabilidade de florestas naturais. IPEF, v.12, n.31, p.79-84, 1998.

GOIS, I. B.; SILVA-MANN, R.; FERREIRA, R. A. Diversidade genética de indivíduos de Spondias lutea L., por meio de isoenzimas. Scientia Forestalis, n.37, p.55-60, 2009.

GOIS, I.B.; FERREIRA, R.A., SILVA-MANN, R.; BLANK, M.F.A.; SANTOS NETO, E.M. Genetic diversity among individuals of Spondias lutea L. originating from Sergipe low San Francisco area using rapd markers. Revista Árvore, v.38, n.2, p.261-270, 2014.

GOMES FILHO, A.; OLIVEIRA, J.G.; VIANA, A.P.; SIQUEIRA, A.P.O.; OLIVEIRA, M.G.; PEREIRA, M.G. Marcadores moleculares RAPD e descritores morfológicos na avaliação da diversidade genética de goiabeiras (Psidium guajava L.). Acta

Scientiarum Agronomy, v.32, n.4, p.627-633, 2010.

GONCALVES, L.O.; PINHEIRO, J.B.; ZUCCHI, M.I.; SILVA-MANN, R. Genetic characterization of the coral tree (Erythrina velutina Willd.) in areas of low occurrence. Revista Ciência Agronômica, v.45, n.2, p.290-298, 2014.

HOLANDA, F. S. R.; SANTOS, C. M.; GUIMARÃES, M. F. R.; ROCHA, I. P.; SANTOS, T.T.; FILHO, R. N. A.; VIEIRA, T. R. S.; CHAGAS; R. M. Monitoramento da erosão em margens de cursos d’água: o caso do rio São Francisco. Fapese, v.4, n.2, p.37-52, 2008.

KAGEYAMA, P. Y. Consevação “in situ” de recursos genéticos de plantas. IPEF, n.35, p.7-37, 1987.

KAGEYAMA, P.Y.; SEBBENN, A.M.; RIBAS, L.A.; GANDARA, F.B.; CASTELLEN, M.; PERECIM, M.B.; VENCOVSKY, R. Diversidade genética em espécies tropicais de diferentes estágios sucessionais por marcadores genéticos. Scientia Forestalis, n.64, p.93-107, 2003.

LORENZI, H.; MATOS, F. J. A. Plantas medicinais no Brasil: nativas e eExóticas. 2.ed. Nova Odessa: Instituto Plantarum, 2008. 544p.

MARTINS-CORDER, M. P.; FIALHO, L. E. B.; ZAMBIAZI, D. C.; KONZEN, E. R. Análise da diversidade genética de populações de palmiteiro (Euterpe edulis MARTIUS) através de marcadores isoenzimáticos. Revista Ceres, v.56, n.2, p.204213, 2009.

Revista Árvore, Viçosa-MG, v.38, n.6, p.1103-1113, 2014 
MOURA, T.M.; SEBBENN, A M.; MARTINS, K.; MORENO, M.A.; OLIVEIRA, G. C.X.; CHAVES, L.J.; KAGEYAMA, P.Y. Allelic diversity in populations of Solanum lycocarpum A. St.-Hil (Solanaceae) in a protected area and a disturbed environment. Acta Botanica Brasilica, v.25, n.4, p.937-40, 2011.

NAIR, V.D.; RAJ, R.P.D.; PANNEERSELVAM, R.; GOPI, R. Assessment of diversity among populations of Rauvolfia serpentina Benth. Ex. Kurtz. from Southern Western Ghats of India, based on chemical profiling, horticultural traits and RAPD analysis. Fitoterapia, v.92, n.1, p.46-60, 2014.

NASCIMENTO, H.E.M.; DIAS, A. S.; TABANEZ, A.A.J.; VIANA, V.M. Estrutura e dinâmica de populações arbóreas de um fragmento de floresta estacional semidecidual na região de Piracicaba, SP. Revista Brasileira de Biologia, v.59, n.2, p.329-342, 1999.

NAZARENO, A.G.; JUMP, A.S. Species genetic diversity correlations in habitat fragmentation can be biased by small sample sizes. Molecular Ecology, v.21, p.2847-2849, 2012.

OLIVEIRA, C.A.M.; SILVA, E.F.; MOLICA, S.G.; FERREIRA, R.L.C.; LIRA, D.A.S.; BARROS JÚNIOR, J.A.B. Diversidade e estrutura genética em populações de Caesalpinia echinata (Lam.) na Estação Ecológica do Tapacurá, PE. Scientia Forestalis, n.70, p.77-83, 2006.

POGGIANI, F.; STAPE, J. L.; GONÇALVES, J. L. M. Indicadores de sustentabilidade das plantações florestais. IPEF, v.12, n.31, p.33-44, 1998.

RABBANI, A. R. C.; SILVA-MANN, R.; FERREIRA, R. A. Variabilidade genética de Genipa americana L. pertencente ao baixo curso do rio São Francisco. Revista Árvore, v.36, n.3, p. 401-409, 2012.

RABBANI, A.R.C.; SILVA-MANN, R.; FERREIRA, R.A. Diversidade genética de indivíduos de Enterolobium contortisiliquum Vell. Morong., por meio de marcadores RAPD no Baixo Rio São Francisco. Revista Árvore, v.36, n.3, p. 401409, 2012.

Revista Árvore, Viçosa-MG, v.38, n.6, p.1103-1113, 2014
REIS, C.A.F.; SOUZA, A.M.; MENDONÇA, E.G.; GONÇALVES, F.R.; MELO, R.M.G.; CARVALHO, D. Diversidade e estrutura genética espacial de Calophyllum brasiliense Camb. (Clusiaceae) em uma floresta paludosa. Revista Árvore, v.33, n.2, p.265-75, 2009.

SANTANA, G. C. ; SILVA-MANN, R. ; FERREIRA, R. A. ; GOIS, I. B. ; BOARI, A. J. ; CARVALHO, S. V. A. Diversidade genética de indivíduos de Enterolobium contortisiliquum Vell. Morong., por meio de marcadores RAPD no Baixo Rio São Francisco. Revista Árvore, v.32, p.427-433, 2008.

SANTOS, A.R.F.; SOUZA, E.M.; SILVA-MANN, R.; FERREIRA, R.A.; SILVA, A.V.C. Perfis enzimáticos de genótipos de Caesalpinia ferrea var. leyostachia e Cassia grandis. Floresta e Ambiente, v.17, n.1, p.37-43, 2010.

SANTOS, W.P.; CARVALHO, A.C.S.; ESTEVAM, C.S; SANTANA, A.E.; MARÇAL, R.M. In vitro and ex vivo anticholinesterase activities of Erythrina velutina leaf extracts.

Pharmaceutical Biology, v.50, n.7, p.919924, 2012.

SILVA, D.S.B.S.; BARBOZA, BENHUR, G.; ANUSKA, C.F.S.; OLIVEIRA, B.; ESTEVAM, C.S.; A. NETO, V.; SANTOS, A.L.L.M.; DIAS, A.S.; SCHER, R.; PANTALEAO, S.M. Investigation of protective effects of Erythrina velutina extract against MMS induced damages in the root meristem cells of Allium cepa. Revista

Brasileira de Farmacognosia, v.23, n.2, p.273-278, 2013.

SILVA, A.V.C.; SANTOS, A.R.F.; WICKERT, E.; SILVA JÚNIOR, J.F.; COSTA, T.S. Divergência genética entre acessos de mangabeira (Hancornia speciosa Gomes). Revista Brasileira de Ciências Agrárias, v.6, n.4, p.572-578, 2011.

SILVA, F.K.G.; LOPES, S.F.; LOPEZ, L.C.S.; MELO, J.I.M.; TROVÃO, D.M.B.M. Patterns of species richness and conservation in the Caatinga along elevational gradients in a semiarid ecosystem. Journal of Arid Environments, v.10, n.1, p.47-52, 2014.

SERGIPE. Secretaria de Estado do Planejamento e da Ciência e Tecnologia - SEPLANTEC. 
Superintendência de Estudos e Pesquisas-SUPES. Informes Municipais. Aracaju: 2000. 75p.

SOUZA, D.C.L.; SILVA-MANN, R.; FERREIRA, R.A; GOMES, L.J.; ALMEIDA, T.S.; OLIVEIRA, A.S; PEREIRA, GS; GOIS, I.B. Produção de frutos e características morfofisiológicas de Schinus terebinthifolius Raddi., na região do baixo São Francisco, Brasil. Revista Árvore, v.37, n.5, p.923-932, 2013.

VALLE, J.S.; FONSECA, B.K.D.; NAKAMURA, S.S.; LINDE, G.A.; MATTANA, R.S.; MING, L.C.; COLAUTO, N.B. Diversidade genética de populações naturais de pariparoba [Pothomorphe umbellata (L.) Miq.] por RAPD.

Revista Brasileira de Plantas

Medicinais, v.15, n.1, p.47-53, 2013.

VIEGAS, M.P.; SILVA, C.L.S.P.; MOREIRA, J.P.; CARDIN, L.T.; AZEVEO, V.C.R.; CIAMPI, A.Y.; FREITAS, M.L.M.; MORAES, M.L.T.;

SEBBENN, A.M. Diversidade genética e tamanho efetivo de duas populações de Myracrodruon urundeuva Fr. All., sob conservação ex situ. Revista Árvore, v.35, n.4, p.769-779, 2011.

VIEIRA, F.A.; CARVALHO, D. Genetic structure of an insect-pollinated and bird-dispersed tropical tree in vegetation fragments and corridors: implications for conservation.

Biodiversity and Conservation, v.17, n.10, p.2305-21, 2008.

WRIGHT, S. Coefficients of imbreeding and relationship. American Naturalist, v.56, p.330-338, 1922.

WINOGRAD, M.; FERNÁNDEZ, N.; FRANCO, R..M. Marco conceptual para el desarrollo y uso de indicadores ambientales $y$ de sustentabilidad para la tomada de decisiones en Latinoamérica y el Caribe. Mexíco: PNUMA-CIAT, 1996. Disponível em: <http:// www.ciat.egiar.org/indicators/unepciat/paper.htm>

YEH, F. C.; YANG, R.; BOYLE, T. POPGENE version 1.32: Microsoft Window-based freeware for population genetics analysis. Edmonton: University of Alberta, 1999. 
